\title{
POLÍTICAS EDUCACIONAIS PARA A EDUCAÇÃO DO CAMPO: dimensões históricas e perspectivas curriculares
}

\author{
Maria Vieira Silva ${ }^{1}$ \\ Astrogildo Fernandes Silva Júnior ${ }^{2}$ \\ Universidade Federal de Uberlândia - UFU
}

\section{RESUMO}

Historicamente, a educação do campo foi relegada a espaços marginais nos processos de elaboração e implementação das políticas educacionais na realidade brasileira. Como pensar os efeitos desses constructos sociais na organização do trabalho das escolas do campo? Quais os sentidos e concepções presentes no percurso histórico da educação no e para o campo? Essas, dentre outras questões, assumirão centralidade nas reflexões presentes neste texto. Enfocaremos os diferentes contornos da história da educação para o campo e as lacunas e potencialidades presentes nas políticas educacionais para essa modalidade de ensino, por meio de três ângulos: a precarização do atendimento escolar à criança pobre do campo; as regularidades e as singularidades para as questões curriculares da educação do campo; as aproximações e distanciamentos entre as proposições dos movimentos sociais do campo e as propostas governamentais no atual cenário educacional. Posteriormente, apresentaremos elementos oriundos de uma pesquisa-ação desenvolvida em comunidades de assentamentos rurais pelo Programa de Apoio Científico e Tecnológico aos assentamentos de Reforma Agrária - PACTo, Minas Gerais/Triângulo Mineiro (CNPq/INCRA/UFU).

Palavras-chaves: Educação do campo; políticas curriculares; assentamentos rurais

\section{EDUCATIONAL POLICIES FOR RURAL EDUCATION: historical dimensions and curricular perspectives}

\begin{abstract}
Historically, rural education has been relegated to marginal spaces in the process of elaboration and implementation of educational policies in the Brazilian reality. How to think the effects of these social constructs in the work organization of rural schools? What are the meanings and concepts present in the historical course of rural education? These, among other issues, will assume centrality in the reflections contained in this text. We focus on the different contours of the rural education history, gaps, and potential present in educational policies for this modality of education, through three angles: the precariousness of school attendance of poor children in rural areas, the regularities and singularities for curricular issues of rural education, the similarities and differences between the proposals of social movements and the government proposals in the current educational setting. Subsequently, we present evidence from a research program developed in communities of rural settlements by the Program of Scientific and Technological Support to Agrarian Reform Settlements - PACTo, Minas Gerais / Triangulo Mineiro (CNPq / INCRA / UFU).
\end{abstract}

Keywords: Rural education; curriculum policies; rural settlements 


\title{
Introdução
}

\author{
Eu venho lá do sertão e posso não te agradar \\ [...] Mas o mundo foi rodando nas patas do meu \\ cavalo \\ $\mathrm{E}$ nos sonhos que fui sonhando, as visões se \\ clareando, as visões se clareando, até que um dia \\ acordei \\ Então não pude seguir valente em lugar tenente \\ E dono de gado e gente, porque gado a gente \\ marca, tange, ferra, engorda e mata, \\ mas com gente é diferente \\ (Disparada - Geraldo Vandré e Théo Bastos)
}

As percepções e discursos sobre o homem e a cultura do campo têm sido tradicionalmente, permeadas por dimensões imagéticas que tendem a inferiorizar, estereotipar e segregar as identidades e subjetividades do meio rural. Uma das possíveis interpretações para esse aspecto - embora não seja a única - diz respeito às sólidas fronteiras entre o espaço urbano e o espaço rural, marcadas por construções culturais hegemônicas do meio urbano, as quais materializam-se sob múltiplas formas e com diferentes alcances no tecido social. Enfocaremos neste trabalho, a partir de uma perspectiva histórica, abordagens analíticas concernentes aos diferentes contornos das políticas educacionais para a educação do campo e seus tênues alcances no contexto escolar. Outro flanco de análise presente no texto, busca colocar em relevo reflexões atinentes às perspectivas curriculares para a educação no campo buscando apreender elementos das singularidades desta modalidade de ensino, sem negligenciar a dimensão universalista da educação escolar. Por fỉm, sintetizaremos uma experiência de pesquisa-ação desenvolvida em comunidades de assentamentos rurais pelo Programa de Apoio Científico e Tecnológico aos Assentamentos de Reforma Agrária PACTo, Minas Gerais/Triângulo Mineiro (CNPq/INCRA/UFU).

O vídeo documentário Caminhos da Escola - Paraná (2007), coloca em tela um complexo diagnóstico da realidade das crianças - filhos de trabalhadores rurais - no que diz respeito ao acesso à escola, em percursos de até 3 horas por dia. Além disso, é possível apreender também no roteiro do filme outros elementos que caracterizam a educação escolar no meio rural, tais como: a existência de professores leigos; precárias infra-estruturas das escolas e das condições das crianças na realização de atividades escolares; intensos processos de evasão escolar. Na dinâmica pedagógica da sala de aula evidencia-se a veiculação de conceitos e conteúdos curriculares alheios à interação das crianças aos mesmos, aspectos esses que também estão presentes nas falas das crianças quando indagadas sobre determinadas questões do aprendizado escolar. Esses elementos, em maior ou menor escala, estão vinculados às políticas educacionais e ao papel do Estado enquanto provedor de bens sociais como a educação. As seções que se seguem colocarão em relevo as contribuições e omissões das políticas educacionais para a educação do campo. 


\section{Políticas educacionais da Educação do campo: origens e percursos históricos}

A constituição e consolidação do sistema escolar no Brasil pautam-se em um paradigma urbano. De acordo com Arroyo (2007), há uma idealização da cidade como espaço civilizatório por excelência, como uma expressão da dinâmica política, cultural e educativa

[...], a essa idealização da cidade corresponde uma visão negativa do campo como lugar do atraso, do tradicionalismo cultural. Essas imagens que se complementam inspiram as políticas públicas, educativas e escolares e inspiram a maior parte dos textos legais. O paradigma urbano é a inspiração do direito à educação. A palavra adaptação, utilizada repetidas vezes nas políticas e nos ordenamentos legais, reflete que o campo é lembrado como o outro lugar, que são lembrados os povos do campo como outros cidadãos, que é lembrada a escola e seus educadores (as) como a outra e os outros (ARROYO, 2007, p. 159).

As consequências dessa subsunção do campo ao paradigma urbano podem ser observadas na própria evolução do sistema de ensino brasileiro. Revisitando a história da educação no meio rural no Brasil, compartilhamos com ARROYO (2004) da seguinte opinião: a escola, no meio rural, foi tratada como resíduo do sistema educacional brasileiro e, consequentemente, à população do campo foi negada o acesso aos avanços ocorridos nas duas últimas décadas, como o reconhecimento e a garantia do direito à educação básica. Conforme Leite (1999),

A educação rural no Brasil, por motivos sócio-culturais, sempre foi relegada a planos inferiores, e teve por retaguarda ideológica o elitismo acentuado do processo educacional, aqui instalado pelos jesuítas e a interpretação políticoideológica da oligarquia agrária conhecida popularmente na expressão: "gente da roça não carece de estudos. Isso é coisa de gente da cidade". (anônimo) (LEITE, 1999, p.14).

A escola rural, no Brasil, foi construída, tardiamente, e sem o apoio necessário por parte do Estado para que se desenvolvesse. Até as primeiras décadas do século XX, a educação era privilégio de poucos, sobretudo, no meio rural. A educação rural não foi nem sequer mencionada nos textos constitucionais até 1891 (Diretrizes operacionais para a educação básica nas escolas do campo, 2002). É evidente, na história da educação brasileira, o descaso das elites dominantes para com a educação pública, particularmente, em relação às escolas rurais. O Grupo Permanente de Trabalho de Educação do Campo ${ }^{3}$ - GPTE - instituído pelo Ministério da Educação em 03/06/2003, reconhece as históricas omissões do Estado neste setor:

O Estado brasileiro omitiu-se: (1) na formulação de diretrizes políticas e pedagógicas específicas que regulamentassem como a escola do campo deveria funcionar e se organizar; (2) na dotação financeira que possibilitasse a institucionalização e a manutenção de uma escola com qualidade em todos os níveis de ensino; (3) na implementação de uma política efetiva de formação inicial e continuada e de valorização da carreira docente no campo (GPTE, 2005, p.7). 
A educação, no meio rural, não se constituiu, historicamente, em um espaço prioritário para uma ação planejada e institucionalizada do Estado Brasileiro. Isso privou a população do campo, em especial, a classe trabalhadora, de ter acesso às políticas e serviços públicos em geral. Este fato contribuiu para o acelerado processo de êxodo rural, registrado a partir da década de 1950. O êxodo rural foi resultado de dois fenômenos: expulsão e atração. A expulsão, no caso brasileiro, aconteceu decorrente da modernização do campo, que privilegiou os grandes latifundiários, não incluindo o agricultor familiar. E a atração que as cidades exerceram no processo de industrialização era, não raro, uma visão idílica, que não correspondia com a realidade dos trabalhadores do campo.

Com a negligência do Estado em relação às escolas rurais, as próprias comunidades se organizaram para criar escolas e garantir a educação de seus filhos, contando, algumas vezes, com o apoio da Igreja, de outras organizações e movimentos sociais comprometidos com a educação popular.

Os problemas da educação no Brasil são muitos, mas, no meio rural, a situação é mais complexa. Os currículos escolares, geralmente, têm dado ênfase aos direitos básicos da cidadania e, portanto, de uma vida digna, reduzida aos limites geográficos e culturais da cidade, negando-se a reconhecer o campo como um espaço social e de constituição de identidades e sujeitos. O GPTE (2005) reforça essa argumentação da seguinte maneira:

A concepção de que o meio rural é um espaço de atraso foi fortalecida a partir da primeira metade do século XX, com o surgimento de um discurso modernizador e urbanizador, que enfatizava a fusão entre os dois espaços, urbano e rural, por acreditar que o desenvolvimento industrial, em curso no Brasil, faria desaparecer dentro de algumas décadas a sociedade rural. Segundo a ideologia da modernização, "o campo é uma divisão sociocultural a ser superada, e não mantida” (GPTE, 2005, p.8).

Analisando a Lei ${ }^{\circ} 5.692 / 1971$, Leite (1999) afirma que a educação rural não foi focalizada ou enfatizada e, sim, destituída de sua identidade. Segundo o autor, desde 1960, a educação rural vem capitulando programas educacionais, via Ministério e Conselhos de Educação, sem, contudo, estabelecer uma filosofia e/ou uma política específica para a escolaridade nas regiões rurais.

Com o golpe militar, em 1964, a política educacional passou a sofrer um processo de mudanças. Os canais de participação e representação popular foram fechados, impedindo a manifestação dos grupos envolvidos. Houve perseguição, prisão e exílio de educadores comprometidos com projetos de educação popular. Esse período foi caracterizado por uma reforma educacional centralizada e excludente ancorada no binômio segurança nacional e desenvolvimento econômico. Leite (1999) lista três intenções implícitas da Lei Federal 5.692/1971,

Utilização do processo escolar, em todos os níveis de escolaridade, como meio de propagação, de divulgação e penetração do ideário nacionalistamilitar do Estado, isto é, fazer prevalecer a ideologia empresarial-estatal;

Controle político-ideológico-cultural, principalmente da classe operária, através da profissionalização e do currículo escolar mínimo desprovido de um conteúdo crítico-reflexivo; 
Recriação de infra-estrutura material e de recursos humanos adequados ao desenvolvimento do capital e da produção (LEITE, 1999, p.26).

Nos anos 1970, na sociedade brasileira, as reações ao autoritarismo, implantado pelo golpe militar vigente, cresceram. Outras possibilidades para a escola rural começaram a ser pensadas de acordo com uma perspectiva crítica. Iniciativas diferentes, situadas no campo da educação popular, política, educação de jovens e adultos passaram a exigir maior participação do Estado no cenário rural brasileiro.

Essas discussões se acentuaram com o debate e a aprovação da Constituição Federal de 1988 e da LDB, Lei de Diretrizes e Bases da Educação Nacional (LDB 9394/96), que propõe, no artigo 28:

Na oferta da educação básica para a população rural, os sistemas de ensino promoverão as adaptações necessárias a sua adequação às peculiaridades da vida rural e de cada região, especialmente:

I - conteúdos curriculares e metodologias apropriadas às reais necessidades e interesses dos alunos da zona rural;

II - organização escolar própria, incluindo adequação do calendário escolar às fases do ciclo agrícola e às condições climáticas;

III - adequação à natureza do trabalho na zona rural. (BRASIL/MEC, LDB 9.394/96, art. 28).

As medidas de adequação da escola à vida do campo não estavam contempladas anteriormente na sua especificidade. Segundo Leite (1999), a LDB promoveu a desvinculação da escola rural dos meios e da performance escolar urbana, exigindo da escola rural um planejamento ligado à vida rural e, de certo modo, desurbanizado. Mesmo diante das mudanças propostas pela Lei, a problemática ligada à escola rural permaneceu. Leite (1999) aponta alguns problemas a serem considerados nos anos 1990:

- Quanto à clientela da escola rural: a condição do aluno como trabalhador rural; distâncias entre locais de moradia/trabalho/escola; heterogeneidade de idade e grau de intelectualidade; baixas condições aquisitivas do alunado; acesso precário a informações gerais.

- Quanto à participação da comunidade no processo escolar: um certo distanciamento dos pais em relação à escola, embora as famílias tenham a escolaridade como valor sócio-moral;

-Quanto à ação didático-pedagógica: currículo inadequado, geralmente, estipulado por resoluções governamentais, com vistas à realidade urbana; estruturação didático-metodológica deficiente; salas multisseriadas; calendário escolar em dissonância com a sazonalidade da produção; ausência de orientação técnica e acompanhamento pedagógico; ausência de material de apoio escolar tanto para professores quanto para alunos; (LEITE, 1999, p. $55-56)$.

Em que pesem as problemáticas apontadas por LEITE (1999), ARROYO (2004) afirma que, nas últimas décadas do século $\mathrm{XX}$, assistimos a uma instigante presença dos sujeitos do campo na cena política e cultural do País. Tais sujeitos se mostram diferentes e exigem respeito. Denunciam o silenciamento e o esquecimento por parte dos órgãos 
governamentais e lutam por uma escola do campo que não seja apenas um arremedo da escola urbana e, sim, uma escola que esteja atenta aos seus sujeitos específicos.

É recorrente no debate educacional, que a educação, no âmbito do estado de direito, constituiu-se em uma ação estratégica para a emancipação e a cidadania de todos os sujeitos que vivem ou trabalham no campo, e pode colaborar com a formação das crianças, jovens e adultos para o desenvolvimento sustentável regional e nacional. É possível considerar a riqueza de saberes que essa população rural produz nas suas experiências cotidianas, e que a agenda de trabalho para discutir e subsidiar a construção de uma política de educação no campo incorpore o respeito à diversidade cultural.

A educação é um direito social. Uma política de educação do campo requer o reconhecimento de que a cidade não é superior ao campo e, a partir dessa compreensão, devese impor novas relações baseadas na horizontalidade e solidariedade entre campo e cidade. $\mathrm{O}$ campo é, acima de tudo, espaço de cultura singular, rico e diverso. Assim, é importante a superação da dicotomia entre o rural e o urbano (ARROYO, 2004).

No interior do debate acerca da identidade da educação escolar rural, SILVA E COSTA (2006) diferenciam o paradigma da educação rural do paradigma da educação no campo. Destarte, vale ressaltar que o conceito paradigma é entendido aqui como o conjunto de referências, valores, conhecimentos que se consolidam na comunidade científica, os quais são incorporados por diferentes instituições e se transformam em um projeto de desenvolvimento territorial. Ele tanto seleciona o que interessa quanto exclui o que não reconhece como verdadeiro para si. Prosseguindo suas análises, Silva e Costa (2006), asseveram que o paradigma da educação rural apóia-se em uma visão tradicional do espaço rural no País e não se propõe a fazer as inter-relações emergentes da sociedade brasileira, nem incorporar as demandas trazidas à sociedade por movimentos sociais e sindicais, que exigem a valorização das especificidades do meio rural. Esse modelo de educação rural torna-se um instrumento de reprodução e expansão de uma estrutura agrária concentradora. Os trabalhadores rurais e suas técnicas são vistos como improdutivos, excluídos, e seus territórios não existem porque não são entendidos como territórios de vida.

O paradigma da educação no campo concebe o campo como espaço de vida e resistência, onde camponeses lutam por acesso à terra e pela oportunidade de permanecer nela. Concebe a diversidade dos sujeitos sociais - agricultores, assentados, ribeirinhos, caiçaras, extrativistas, pescadores, indígenas, remanescentes de quilombos, enfim, todos os povos do campo brasileiro. Reconhece a importância da agricultura familiar ao reconhecer a diversidade do campo brasileiro. Além disso, no processo de redemocratização do Brasil, fortaleceram as lutas e a organização dos movimentos sociais como, por exemplo, o Movimento dos SemTerra - MST -, cuja agenda de reivindicações prevê a extensão de direitos, como a educação. Essas mudanças no campo implicam a necessidade de um novo paradigma da educação do campo.

O Grupo Permanente de Trabalho e Educação no Campo (2005) defende os seguintes princípios pedagógicos de uma Educação do Campo: 1) o papel da escola é formar sujeitos, e isso deve articular-se a um projeto de emancipação humana; 2) é valorizar os diferentes saberes oriundos da diversidade de sujeitos no processo educativo; 3 ) é valorizar os diferentes espaços e tempos de formação dos sujeitos da aprendizagem, pois a educação no campo ocorre tanto em espaços escolares quanto fora deles; 4) é vincular a escola à realidade dos sujeitos; 5) é ter a educação como estratégia para o desenvolvimento sustentável; 6) desenvolver a autonomia e colaboração entre os sujeitos do campo e o sistema nacional de ensino. 
Com base nesses princípios, a discussão em torno do ensino em escolas rurais ganha relevância. Discutir sobre o que ensinar e a quem, na escola, sempre demandam novas análises, novos ângulos, novas perspectivas.

\section{Perspectivas curriculares para a educação no campo}

O ensino pode se desenvolver por meio das formas mais variadas de construção e reconstrução do espaço físico e simbólico, do território, dos sujeitos, do meio ambiente das culturas escolares. Segundo FORQUIN (1992), existe um pluralismo cultural no interior das comunidades, os próprios indivíduos não escapam à lei geral da diferenciação interna. Se cada escola é única, incorpora uma diversidade de sujeitos, identidades plurais, gêneros, etnias, religiosidades, alunos e professores de culturas diferentes. Essas questões são constitutivas de um projeto político de educação do campo que se pretenda emancipatório.

A educação emancipatória, para FREIRE (1988), é aquela que estimula a opção pela afirmação do homem como homem. Para o autor, o destino do homem deve ser criar e transformar o mundo, sendo o sujeito de atuação. A educação é pautada no diálogo, o qual define como uma relação horizontal de A com B. A concepção de educação em Paulo Freire, como processo de humanização do sujeito, com vistas à intervenção na realidade, marca o currículo emancipatório que tem no diálogo a indispensável relação com o ato cognoscente, desvelador da realidade. O diálogo nasce de uma matriz crítica e gera criticidade. O diálogo é, portanto, o caminho indispensável não somente nas questões vitais para nossa ordem política, mas em todos os sentidos da nossa existência.

Embora Paulo Freire não tenha elaborado produções específicas sobre o currículo, questões curriculares tangenciam suas obras. Sob a perspectiva epistemológica, reconhece a condição de sujeito dos que buscam produzir o conhecimento, na afirmação da finalidade da educação para o desenvolvimento humano e social, como processo contínuo que respeita os diferentes saberes e culturas, constituindo-se as bases para um currículo que responda à diversidade cultural. Para o autor, a educação deve proporcionar aos sujeitos a possibilidade de refletir e questionar a realidade, de maneira crítica: "neste sentido, a educação libertadora, problematizadora, já não pode ser o ato de depositar, ou narrar, ou de transferir, ou de transmitir 'conhecimentos' e valores aos educandos, meros pacientes, à maneira da educação ‘bancária`, mas um ato cognoscente (Freire, 1988, p.78). Destarte, um dos grandes desafios da prática educativa escolar é garantir legitimidade e respeito aos saberes que os educandos, sobretudo os da classes populares, levam para a escola, tornando-se fundamental discutir com os alunos a razão de ser de alguns desses saberes em relação com o ensino dos conteúdos. Nesta direção, Freire (1996) questiona: "Porque não estabelecer uma necessária "intimidade" entre os saberes curriculares fundamentais aos alunos e a experiência social que eles têm como indivíduos? Por que não discutir as implicações políticas e ideológicas de um tal descaso dos dominantes pelas áreas pobres da cidade? Há ética de classe embutida neste descaso? [...] Porque, dirá um educador reacionariamente pragmático, a escola não tem nada que ver com isso. A escola não é partido. Ela tem que ensinar os conteúdos, transferi-los aos alunos. Aprendidos, estes operam por si mesmos (p. 34).

Em sua proposta, o educando tem a possibilidade de problematizar a realidade, estabelecendo conexões com os conteúdos curriculares, ou seja, os conhecimentos são portadores de uma explicação do real e não algo estático e abstrato. Portanto, as bagagens 
culturais e o conhecimento de mundo que os educandos portam, tornam-se ricas "matériasprimas" no processo de aprendizagem. Dessa forma, temas trabalhados no contexto educacional, surgem do interesse e da vivência do próprio grupo. Tais temas são denominados por Freire de Temas Geradores, uma vez que estes são apenas o ponto de partida para o conhecimento. Freire (1996) afirma que a formação não é algo estático e a-político e a aprendizagem deve basear-se numa relação dialógica em que tanto o educando quanto o educador enriquecem seus conhecimentos, assim,

não é possível respeito aos educandos, à sua dignidade, a seu ser formandose, à sua identidade fazendo-se, se não se levam em consideração às condições em que eles vem existindo, se não se reconhece a importância dos 'conhecimentos de experiência feitos' com que chegam à escola. $\mathrm{O}$ respeito devido à dignidade do educando não me permite subestimar, pior ainda, zombar do saber que ele traz consigo para a escola (FREIRE, 1996, p. 46).

As perspectivas pedagógicas postuladas por Freire têm sido referenciadas por autores que defendem uma educação para o campo. Além das bases epistemológicas e gnosiológicas contidas na proposta de Freire, estudiosos, como ARROYO (2007), CALDART (2004), MOLINA (2004), questionam e contrapõem-se a transposição do conhecimento das escolas urbanas para as rurais, criticando a visão "urbanocêntrica" e as propostas desenvolvimentistas para o campo, centradas, principalmente, no agronegócio e na exploração dos recursos naturais. Para tanto, ressaltam a importância de se contemplarem, nas propostas curriculares para o campo uma nova base paradigmática pautada nas reflexões em relação à diversidade, à sustentabilidade ambiental, agrária, agrícola, social, econômica, política e cultural, assim como a eqüidade de gênero, geração, étnico-racial e a diversidade sexual, constituindo-se, assim, em um reconhecimento do direito dos povos do campo a uma educação que vai além da concepção de espaço geográfico e compreende as necessidades culturais e a formação integral das pessoas. Sob tal ângulo, faz-se necessário romper com a visão de que o campo é um espaço atrasado, de ignorância, sem cultura, sem vida, sem identidade. Mais do que fazer um "remendo", é preciso humanizar e legitimar as dimensões políticas e pedagógicas da educação básica no campo.

Nesse sentido, ARROYO (2004) esclarece que a escolaridade rural deve ter como objetivo principal proporcionar conhecimentos, cidadania e continuidade cultural. A escola, ao ser levada ao campo, depara-se com as mais diversificadas formas de processos produtivos, culturas heterogêneas, clientelas diferenciadas, com valores e aspirações próprias. Para Leite (1999):

A função primordial da escola é ensinar, transmitir valores e traços da história e da cultura de uma sociedade. A função da escola é permitir que o aluno tenha visões diferenciadas de mundo e de vida, de trabalho e de produção, de novas interpretações de realidade, sem, contudo, perder aquilo que lhe é próprio, aquilo que lhe é identificador (LEITE, 1999, p. 99).

A terra, o meio ambiente e sua relação com o cosmo, a democracia, a resistência e a renovação das lutas e dos espaços físicos, assim como as questões sociais, políticas, culturais, econômicas, científicas e tecnológicas, são elementos transversais na educação do campo (GPTE, 2005). Assim, concordamos com os autores que defendem um projeto 
educativo que se realize na escola e que esta precisa ser do campo e no campo e não para o campo.

Segundo Brandão (2003):

A tentativa de redução dos índices de evasão e repetência, sobretudo entre as camadas de alunos carentes, é sempre limitada quando realizada através da introdução de inovações simples de currículo e da aplicação de métodos, cuja eficácia, sem dúvida, é maior, quando em testes de laboratório. Uma das causas da distância entre os resultados experimentais e o trabalho escolar com novos métodos está em que o professor, principalmente o professor que trabalha, ele próprio, em escolas carentes, não pode, ou não quer trabalhar com o método tal como ele foi pensado (BRANDÃO, 2003, p. 138).

É importante que a educação no campo se coloque na luta pelos direitos: direito ao saber, ao conhecimento, à cultura produzida socialmente. ARROYO (2004) considera a educação como direito do homem, da mulher, da criança, do jovem do campo. Para o autor, é fundamental que a educação pense o desenvolvimento levando em conta os aspectos da diversidade, da situação histórica particular de cada comunidade, os recursos disponíveis, as expectativas, os anseios dos que vivem no campo. O currículo das escolas do campo pode estruturar-se fundamentado em uma lógica de desenvolvimento que privilegie o ser humano na sua integralidade, possibilitando a construção da sua cidadania e inclusão social, colocando os sujeitos do campo de volta no processo produtivo com justiça, bem-estar social e econômico. CANIVEZ (1991), em sua obra: "Educar o cidadão", apresenta o problema da educação dos cidadãos, discutindo diversas concepções de Estado e de cidadania que se desenvolveram ao longo dos tempos, sem perder de vista os diferentes modos de organização social que as ensejaram. Entendemos que formar o cidadão não significa domesticá-lo, instruindo-o a cumprir deveres e a expor os seus direitos. Formar o aluno cidadão é formar o sujeito, capaz de fazer uma análise crítica da realidade que o cerca, dos lugares da experiência, não reduzindo a experiência aos lugares e tempos próximos como também a correlacionando aos outros espaços e tempos.

Sem embargo, é necessário a implementação de políticas públicas que fortaleçam a sustentabilidade dos povos do campo, e os sujeitos devem estar atentos para o fato de que existem diferenças de ordem diversa entre os povos do campo. O campo é heterogêneo, muito diverso. Assim, não se pode construir uma política de educação idêntica para todos os povos do campo. Consoante com ORTEGA E FONSECA (2004), devem-se articular as políticas nacionais às especificidades de cada região. ARROYO (2004) refere que a escola deve ser vinculada ao mundo do trabalho, da cultura, ao mundo da produção, à luta pela terra e ao projeto popular de desenvolvimento do campo. É preciso superar a visão de que a cultura do campo é estática, voltada para a manutenção de formas e valores arcaicos.

Pensar a educação do campo é pensar em estratégias que ajudem a reafirmar identidades do campo. Neste sentido, o governo brasileiro instituiu as Diretrizes Operacionais para a Educação básica nas Escolas do Campo, aprovadas pelo Conselho Nacional de Educação - Resolução CNE/CEB, n. 1, de 03 de abril de 2002. O documento é fruto da ação do Grupo Permanente de Trabalho de Educação do Campo (GPTE), que consolidou reivindicações históricas das organizações e movimentos sociais que lutam por uma educação de qualidade para os diversos sujeitos, povos com identidades diversas que vivem no campo, 
como: agricultores familiares, trabalhadores rurais sem terra, quilombolas, assalariados rurais, povos da floresta, ribeirinhos, pescadores, extrativistas e outros. Ressalta-se que em fevereiro de 2004, o governo brasileiro criou, na estrutura do Ministério da Educação e Cultura (MEC), a Secretaria de Educação Continuada, Alfabetização e Diversidade (SECAD), que conta com a Coordenação Geral da Educação no Campo.

Segundo as Diretrizes Operacionais para a Educação básica nas Escolas do Campo, a identidade da escola do campo é definida da seguinte maneira:

Art. 2 - Parágrafo único. A identidade da escola do campo é definida pela sua vinculação às questões inerentes à sua realidade ancorando-se na temporalidade e saberes próprios dos estudantes, na memória coletiva que sinaliza futuros, na rede de ciência e tecnologia disponível na sociedade e nos movimentos sociais em defesa de projetos que associem as soluções exigidas por essas questões à qualidade social da vida coletiva do País (BRASIL, 2002, p.37).

O longo caminho da construção do processo identitário das escolas do campo foi marcado por avanços e retrocessos. Com base nas Diretrizes Operacionais para a Educação básica nas Escolas do Campo, é possível confirmar o potencial organizativo de grupos que lutam pela materialização do direito à educação do campo, ensejando ações da esfera governamental que se materializaram em políticas públicas. Com efeito, a aproximação de movimentos sociais do campo com as instâncias governamentais foi fundamental colocar em relevo nos documentos oficiais a ênfase sobre a preservação das identidades desta realidade singular. Assim, em grande medida, as políticas para a Educação do campo resultam das reivindicações, das experiências dos movimentos sociais do campo em torno de concepções e de políticas de educação para os povos do campo, valorizando dimensões sócio-culturais que são próprias a esse espaço.

Com efeito, na década 1990, potencializou-se a força dos movimentos sociais do campo, sendo que juntamente com o direito a terra e ao trabalho, pautou-se também o direito à educação. Sem embargo, os movimentos sociais colocam a luta pela educação no campo dos direitos e foram desenvolvidos programas educacionais voltados à formação inicial e continuada dos professores das escolas do campo. Além disso,

Investigam-se práticas e políticas educacionais no âmbito da academia, ao mesmo tempo em que a universidade aproxima-se dos povos do campo por meio de projetos de ensino, extensão e de pesquisa. Elaboram-se materiais pedagógicos que retratam a luta pela Educação do Campo e sugerem conteúdos a derem enfatizados nos processos educativos formais. Ampliamse os canais de participação dos trabalhadores e também o aparato legislativo, numa realidade de contínuos enfrentamentos quando se está em pauta a luta pela terra e pelo direito a educação. Reiteram-se as polêmicas e os enfrentamentos políticos quanto à oferta de educação aos povos do campo e à justiça social (SOUZA, 2010, p. 445).

O potencial mobilizador dos movimentos sociais do campo também é reconhecido por ARROYO (2004) e (2007) ao reafirmar argumentos acerca de suas virtualidades formadoras, sugerindo que os mesmos podem constituir-se em um princípio, uma matriz educativa em 
nossas sociedades. Sob tal ótica os movimentos sociais contribuem para um redesenho da teoria pedagógica e do fazer educativo tanto no âmbito das propostas de educação formal quanto informal, sendo o aprendizado dos direitos uma dimensão educativa.

Com efeito, os movimentos sociais colocam a luta pela educação no campo dos direitos e impulsionam a formulação e implementação de diferentes propostas, colocando a educação do campo na pauta das políticas governamentais. Além de políticas curriculares e dos dispositivos legais, os espaços acadêmicos são demandados a atuarem como co-partícipes de ações formadoras para sujeitos envolvidos com a educação do campo, mediante cursos como, Especialização em Educação no Campo; Escola Latino-Americana de Agroecologia; Licenciatura em Educação do Campo; Pedagogia da Terra, dentre outros. Além desses cursos, o Programa de Educação na Reforma Agrária (PRONERA), oriundo das discussões desenvolvidas no I Encontro Nacional de Educadores da Reforma Agrária (ENERA) realizado em 1997, tem se configurado como o principal programa de educação no âmbito da reforma agrária.

Pela força e luta dos movimentos sociais e sindicais, o referido Programa foi criado em 16 de abril de 1998, por meio da Portaria n 10/98 (BRASIL, 1998), vinculado, inicialmente, ao então Ministério Extraordinário da Política Fundiária, e, hoje, ao Ministério do Desenvolvimento Agrário, incorporado, a partir de 2001, ao INCRA. Constituído inicialmente como política de governo, o PRONERA ascendeu ao status de política de Estado em 04 de novembro de 2010, pelo Decreto n. ${ }^{\circ}$ 7.352/2010 (BRASIL, 2010), ampliando o atendimento às populações do campo e ratificando de maneira explícita a centralização da sua gestão no âmbito do INCRA (SILVA e LÉLIS, 2012).

Elegendo, inicialmente, a Educação de Jovens e Adultos como modalidade prioritária de atendimento, o PRONERA tem como metas, dentre outras, a alfabetização dos assentados, a escolaridade dos monitores, a formação continuada de educadores e a formação de técnicos para a produção agropecuária e de gestores para o empreendimento rural, a fim de fortalecer a educação nas áreas de reforma agrária (BRASIL, 2011).

No cotidiano dos movimentos sociais e sindicais, a educação estabelece-se como princípio fundante ao lado da luta pela distribuição de terra e contra o capital (MOLINA, 2009). Portanto, educação e movimentos sindicais agrários tecem um encadeamento de materialidades e simbolismos que entremeiam os seus princípios e fundamentos. Para estes movimentos, a educação constitui-se em item prioritário nas suas agendas de luta social, porque representam resistência a projetos conservadores de educação e se voltam para a defesa de um projeto popular (ARROYO, 2007). Educar os sujeitos dos movimentos significa, antes, educar para a luta e a resistência contra a organização social fundada nos princípios do capital. A independência dos movimentos sociais e sindicais em relação ao objeto que negam é fundamental para que possam superá-lo (MÉSZÁROS, 2011). Ou seja, é preciso que eles sejam capazes de alcançar a dimensão positiva de proposição de uma alternativa hegemônica, demonstrando a sua capacidade de superar o existente.

Sem embargos, os sujeitos dos movimentos envolvidos trazem para o campo universitário seus ideais, modos de pensar o mundo e agir nele, imprimindo a esse espaço novos contornos, influenciando o seu modo de fazer e pensar a educação. Desenham-se novas bases teórico-metodológicas para o currículo, novas configurações na concretude da educação, dado que a confluência das determinações emerge das duas vertentes desse processo: o ambiente universitário incide, material e ideologicamente, sobre os movimentos sindicais agrários, que lhe imprimem de volta muito da sua forma e conteúdo (SILVA e LÉLIS, 2012). 
Sob influência desse contexto, a Universidade Federal de Uberlândia foi instada a contribuir com esse processo, mediante a implementação do "Programa de Apoio Científico $e$ Tecnológico aos Assentamentos de Reforma Agrária - PACTo, Minas Gerais/Triângulo Mineiro", mediante uma parceria entre UFU, CNPq e INCRA, conforme abordaremos na seção que se segue.

\section{Em foco: trajetórias educativas percorridas com os movimentos sociais do campo}

Partilhamos com CALDART (2004), o pressuposto que as políticas públicas devem assegurar uma educação que seja no e do campo: "No: o povo tem direito a ser educado onde vive; Do: o povo tem direito a uma educação pensada desde o seu lugar e com a sua participação, vinculada a sua cultura e às suas necessidades humanas e sociais" (pp 149-150). Para a autora, a perspectiva da luta dos povos do campo por educação ocorre no campo das políticas públicas, porque busca universalizar o acesso de todo o povo à educação, porém uma educação de qualidade, uma educação que forme pessoas como "sujeitos de direito", assim, preconiza também que "é preciso colocar o debate no âmbito geral da educação e no debate de um projeto popular de desenvolvimento do país" (idem, ibidem). No que tange às dimensões curriculares para uma educação no e do campo, os movimentos sociais do campo, defendem que sejam incluídas temáticas como questões relativas ao equacionamento da terra ao longo da história, as tensões no campo entre o latifúndio e a monocultura, o agronegócio e a agricultura familiar; problemas da reforma agrária, a expulsão da terra, os movimentos de luta pela terra e pela agricultura camponesa, pelos territórios dos quilombos e dos povos indígenas. Para Arroyo, "um projeto educativo, curricular, descolado desses processos de produção da vida, da cultura e do conhecimento estará fora do lugar" (ARROYO, 2007, p.167).

Concordamos com tais princípios, no entanto, defendemos o pressuposto que tais perspectivas presentes para o currículo escolar não devem ficar circunscritas apenas ao segmento de professores que atuam no campo. Embora em determinados contextos torne-se necessária a verticalização dessas temáticas, tais proposições voltadas apenas para o território rural poderá acentuar perspectivas ruralistas e segregadoras da educação do campo. Por isso, as singularidades da educação no campo não poderão ser subsumidas à perspectiva universalista, tampouco seu oposto deverá sobrepor-se. Os educandos que vivem no campo, a nosso ver, devem ter acesso também aos códigos culturais produzidos historicamente pela humanidade, socializados e veiculados nas escolas urbanas e vice-versa.

Fundamentadas por tal convicção desenvolvemos no âmbito da Universidade Federal de Uberlândia, o "Programa de Apoio Científico e Tecnológico aos Assentamentos de Reforma Agrária - PACTo, Minas Gerais/Triângulo Mineiro", por meio de uma parceria entre UFU, CNPq e INCRA. O projeto, em sua totalidade, foi composto por três grandes áreas: educação, saúde e produção, contando com a participação de dezesseis docentes pertencentes aos quadros dessa universidade; vinte e cinco estudantes dos diferentes cursos de graduação da instituição e sete profissionais de nível superior. Foram implementados vinte projetos de pesquisa e mais de sessenta atividades de intervenção no interior de quatro assentamentos de reforma agrária situados na Região do Triângulo Mineiro: os assentamentos Zumbi dos Palmares e Rio das Pedras, no município de Uberlândia, e Ezequias dos Reis e Bom Jardim, em Araguari. 
As ações foram pensadas, planejadas e executadas de forma integrada, observando os princípios metodológicos do trabalho coletivo, da multidisciplinaridade e de parcerias interinstitucionais. Esta última opção possibilitou envolver, além das três instituições diretamente responsáveis pelo Programa (UFU, CNPq e INCRA), vários outros organismos oficiais ligados às questões do campo ou da reforma agrária, as prefeituras dos municípios onde estão localizados os assentamentos, os movimentos de luta pela terra e os próprios moradores assentados.

Descreveremos, de forma sumária, as atividades desenvolvidas no âmbito da área de educação, em específico. O projeto nucleador desta área foi intitulado Educação e História Cultural nos Assentamentos de Reforma Agrária: Trajetórias Percorridas, Identidades em Construção integrando oito planos de trabalhos. As metas estabelecidas por este Programa visaram desenvolver atividades intervencionistas e investigativas no interior dos quatro assentamentos supra-mencionados.

O eixo temático nucleador foi "Educação Escolar, Educação Popular e História Cultural" que, por sua vez, se desdobrou em 4 (quatro) sub-eixos, os quais constituem os planos de trabalhos da equipe de professores pesquisadores e os bolsistas de iniciação científica, a saber: Movimentos sociais no campo em uma nova perspectiva de educação; Processo de ensino-aprendizado nas séries iniciais do ensino fundamental e constituição de sujeitos: subjetividades em movimento no cotidiano da escola; A Etnomatemática e o cotidiano das escolas dos assentados; Trabalho, família e educação: História das mulheres nos assentamentos de Uberlândia e Araguari.

Tais linhas de trabalho, articuladas entre si e com as áreas de Produção e Saúde, tiveram como propósito básico contribuir com a promoção do desenvolvimento sustentável nos quatros assentamentos de reforma agrária supracitados, e indiretamente, nas comunidades de seu entorno. As atividades desenvolvidas pelo projeto pautaram-se nas dimensões intervencionistas e investigativas com o apoio de entidades parceiras como as Prefeituras Municipais de Uberlândia e Araguari, as Associações dos Assentados, os Movimentos Sociais e Escolas que atendem os assentamentos, dentre outros, configurando a dimensão de trabalho coletivo que norteou todas as atividades desenvolvidas.

As atividades de pesquisa e intervenção da área de educação tiveram suas especificidades e objetos de estudo com natureza própria, no entanto, a equipe de pesquisadores se propôs a desenvolver o trabalho a partir de uma perspectiva multidisciplinar e interinstitucional estabelecendo conexões com as áreas de Produção e Saúde por meio das diferentes ações que se efetivam no interior dos assentamentos, conforme descrição das atividades realizadas. Assim, foram desenvolvidas várias ações de forma integrada com as áreas de saúde e produção, tais como: mecanismos para contribuir com a elevação da escolarização dos assentamentos e erradicação do analfabetismo; promoção de atividades culturais e desenvolver atividades de assessoria às diversas manifestações educativas e culturais ocorridas nos assentamentos; criação do "Cine Pacto".

Esta atividade, especificamente, propiciou momentos de debates e reflexões associadas ao entretenimento e socialização da equipe. Realizamos ainda palestras no interior dos assentamentos com temas variados, tais como: cooperativismo; Associação; Família; Trabalho; Reforma Agrária; Relações Sociais de Gênero, etc. Foram ainda efetivadas ações relacionadas às dinâmicas organizativas dos assentamentos mediante a constituição de equipes de apoio conforme afinidades com as temáticas discutidas ao longo do projeto, visando à implementação das atividades previstas e propostas juntamente com os assentados, uma vez 
que tais proposições surgiram da própria comunidade; organização de bibliotecas, gibiteca, brinquedoteca e videotecas nos assentamentos; sistematização por meio de registros as manifestações artístico-culturais dos trabalhadores assentados; implementação de ações visando a formação continuada de profissionais da educação que atendem os assentamentos vinculados ao PACTo; atividades de inclusão digital; assessoria ás atividades das Associações de Mulheres dos Assentamentos. Dentre as ações no âmbito dessa meta destacaram-se: participações em assembleias gerais dos assentamentos, contribuição para fundação da Associação das Mulheres do Assentamento Rio das Pedras - AMARP; reuniões sobre Programa Nacional de Desenvolvimento da Agricultura Familiar; oficina de Associativismo; oficina de Formação; Oficina de Elaboração de Projetos e Captação de Recursos; oficina de Confecção de Embalagens; reuniões a fim de organizar feira e comercializar produtos; reunião para organização documental e resgate da história das associações.

As oficinas de Associativismo para as associações de mulheres e/ou grupos de mulheres foram realizadas visando incentivar a participação das mulheres em seu processo de organização coletiva. Foram confeccionadas cartilhas e realizadas assessorias com advogados contando com ampla participação das mulheres que interessaram muito na temática. As ações do Curso de Associativismo desdobraram na produção de uma Carta de Princípios enfocando os seguintes tópicos: Direito de autonomia das Associações das Mulheres; Direito à Liberdade e Dignidade em Igualdade de Direitos; Direito à Informação e Educação; Direitos Econômicos, Sociais e Culturais das Mulheres; Direitos à Saúde e Previdência; Direito das Mulheres lutarem pelo Direito à Terra e a Moradia com Igualdade; Direito de Equidade Racial-Étnica; Dever de Respeitar e Proteger os Direitos da Comunidade; Dever de Lutar pela Conquista e Ampliação desses Direitos.

Quanto às atividades de Educação Popular, foi uma dimensão educativa que ocorreu de forma tangencial em todos os planos de trabalho e ancorou-se no respeito aos saberes, representações, práticas, codificações, costumes, manifestações culturais que as comunidades dos assentamentos portam. Esses saberes evidenciam a história cultural das comunidades dos assentamentos e nos mostrou claramente o corpo de conhecimentos e o objeto de aprendizagem que são historicamente repassados de geração a geração no que diz respeito aos diversos aspectos da vida das comunidades expressos na sua percepção de mundo e nas práticas que se travam nas inter-relações. A interação com esse universo e sua caracterização foram importantes para que os pesquisadores/educadores pudessem se situar dentro de um conjunto de conhecimentos que os assentados apresentavam. Essa foi uma condição necessária para proceder aos encaminhamentos que auxiliaram nas aprendizagens e procederam aos registros que cada um a partir de sua subjetividade e a partir da singularidade de seu projeto de trabalho apreendeu e constituiu-se em fonte de aprendizado para toda a equipe.

No que tange ao trabalho com a educação de adultos no âmbito dos assentamentos de reforma agrária que integraram o Programa, adotamos a perspectiva Freireana como base para elaborar a proposta curricular e subsidiar o trabalho das professoras e das bolsistas do PACTo.

Ao nos referirmos a Proposta Curricular, estamos adotando a mesma perspectiva postulada por Kramer (2001) ao afirmar que "não estabeleço diferença conceitual entre proposta pedagógica e currículo. Compreendo, assim, currículo ou alternativa curricular de forma ampla, dinâmica e flexível, que é freqüentemente a maneira como se tem concebido uma proposta pedagógica". Nesta direção, também Sacristán assevera que: 
Se por currículo entende que, um projeto global e integral de cultura e de educação, no qual se deve observar não apenas objetivos relacionados com conteúdos de matérias escolares, mas também outros que são comuns a todas elas ou que ficam à margem das mesmas, o conceito de Projeto Educativo é a mesma coisa que Projeto Curricular para essa escola. Diferenciar ambos suporia dar ao currículo a concepção restrita que o torna equivalente a compêndio-resumo de matérias ou conteúdos de conhecimento. Significaria manter uma separação artificial entre ensino e educação que, além do mais, não é conveniente. Portanto, adotamos uma posição que torna equiparável ambos os projetos, embora no momento de realizar o projeto da escola, o plano de conteúdos de ensino, que se refere a matérias ou áreas, adquire uma atenção específica" (SACRISTÁN, 1998. p. 245).

Tendo como referência essas concepções de proposta curricular, a dinâmica do trabalho pedagógico e investigativo nas comunidades dos assentamentos de reforma agrária se pautou em duas vertentes que se entrecruzam:

- abordagens do trinômio educação-cultura-política;

- conteúdos convencionais das áreas disciplinares das ciências.

Para a primeira vertente, abordagens do trinômio educação-cultura-política, foram eleitos temas culturais que comumente são silenciados no currículo escolar. Segundo CORAZZA (1997) como forma de selecionar e organizar o currículo, os temas culturais trazem para a cena os conhecimentos subjugados, aqueles que nem sempre foram pensados que poderiam vir a ser constituídos como conhecimentos escolares. Por isso enfocam, deliberadamente, questões relativas a gênero, classe, raça, etnia, religião, identidade nacional, diferenças sexuais, discriminação de idade, colonialismo etc, e todos os conhecimentos que costumam integrar a cultura chamada de popular.

A segunda vertente conteúdos convencionais das áreas disciplinares das ciências enfocaram prioritariamente elementos considerados clássicos de diferentes áreas das ciências. Segundo Sacristán,

o termo conteúdos nos é apresentado carregado de uma significação antes intelectualista e culturalista, própria da tradição dominante das instituições escolares nas quais foi forjado e utilizado. Ao mencioná-lo, pensamos em elementos de disciplinas, matérias, informações diversas e coisas assim. Por conteúdo se entenderam os resumos de cultura acadêmica que compunham os programas escolares parcelados em matérias e disciplinas diversas" (SACRISTÁN, 1998:75).

Em que pesem as críticas à dimensão reducionista convencionalmente atribuída aos conteúdos curriculares, Sacristán (1998), prossegue afirmando que os conteúdos "compreendem todas as aprendizagens que os alunos devem alcançar para progredirmos direções que marcam os fins da educação numa etapa de escolarização, em qualquer área ou fora delas, e para tal é necessário estimular comportamentos, adquirir valores, atitudes e habilidades de pensamentos além de conhecimentos” (IDEM, p.76).

Para levar a efeito nossos propósitos adotamos uma metodologia concebida com base nos princípios da perspectiva crítica, fundada na prática da leitura de mundo, considerando-se a realidade do educando e levando em consideração suas curiosidades, por meio da 
"dialogicidade". Para tanto, optamos pelo referencial teórico identificado com os pressupostos metodológicos de Paulo Freire e Carlos Rodrigues Brandão. Nessa linha, a prática pedagógica pressupõe uma construção coletiva em que a participação do educando e do educador como sujeitos do processo se paute em uma relação dialógica, dinâmica, contínua e principalmente crítica, que tenta resgatar a cultura e a cidadania dos sujeitos envolvidos.

O desenvolvimento deste projeto, os aprendizados propiciados pelas comunidades dos assentamentos e pela comunidade acadêmica reafirmam nossas certezas sobre a necessidade e a viabilidade da interlocução entre as dimensões universalistas e particularistas do currículo e das políticas educacionais para a educação do campo. Tradicionalmente, o currículo escolar tal como se encontra organizado, corporifica formas dominantes de capital cultural, legitimando as histórias eurocêntricas, patriarcais, classistas, ao mesmo tempo em que marginaliza as experiências e as memórias culturais dos assim chamados estudantes das "minorias" (GIROUX, 1995). Assim, veiculam-se de forma manifesta ou tácita noções particulares sobre conhecimento e organização da sociedade, prescrevendo qual conhecimento é legítimo ou ilegítimo e quais grupos sociais podem ser excluídos de representação. Neste caso, as decisões curriculares acerca de o quê ensinar ficam desconectadas das dimensões de cultura e poder sendo que o currículo contribui para reforçar divisões sociais referentes à classe social, etnia e gênero e, em específico, para reforçar as dicotomias campo/cidade, as quais, em menor ou menor escala, alimentam subliminarmente a crença de que um currículo para a educação no campo tende a ser inferiorizado ou como instrumentos de controle de grupos subalternizados.

Ainda de acordo com GIROUX (1995), os movimentos sociais assumem esse desafio ao questionar as escolas que usam o conhecimento acadêmico para emudecer os estudantes. Eles contestam a forma como as diferenças culturais de grupos subordinados são, com frequiência, reguladas e controladas de forma a impedir os estudantes de se basearem em suas próprias histórias e experiências culturais. Nessa linha, o autor acredita que os Estudos Culturais ampliam nossa compreensão do pedagógico e de seu papel fora da escola como local tradicional da aprendizagem e rejeitam o pressuposto de que os professores são simplesmente transmissores de configurações existentes de conhecimento, estando implicados na dinâmica do poder que produzem, medeiam e legitimam em suas salas de aula.

Por outro lado, temos convicção que levar em conta as especificidades do povo do campo não significa perder de vista as dimensões universalistas do currículo, ou seja, é fundamental, garantir as identidades e singularidades desta realidade específica, mas também o acesso à ciência, a tecnologia, aos conhecimentos considerados clássicos e eruditos, evitando repetições binárias entre campo e cidade, que marcam a trajetória histórica desses dois espaços sociais.

O desafio que se coloca é então romper com a hegemonia da excelência urbana que circulam no imaginário social, mediante a imagem do aluno da educação rural como menos apto, "incapaz", e por isso as dinâmicas curriculares tendem a ser de inferiorizadas. Partindo dessa perspectiva, a escola enquanto espaço de luta, poderá desconstruir ou transgredir determinadas formas de conhecimento oficial e de concepção de organização da sociedade, considerando a heterogeneidade de culturas dos diferentes grupos sociais sem que isso signifique binarismos presentes no currículo escolar os quais podem dicotomizar e fracionar um currículo para o campo e um currículo para a cidade; um currículo para a luta e um currículo para o acesso aos saberes científicos; um currículo para o exercício da cidadania e um currículo acadêmico. 


\section{Referências}

ARroYO, M. G; CALDART, R. S. MOLINA, M. C. (Orgs.) Por uma educação do campo. Petrópolis, RJ: Vozes, 2004.

ARROYO, M. G. Políticas de formação de educadores(as) do campo. Caderno CEDES, Campinas, vol.27, n.72, mai/ago 2007.

BRANDÃO, C. R. O que é Educação. (33a ed). São Paulo: Brasiliense, 1995.

A pergunta a várias mãos: a experiência da partilha através da pesquisa na educação. São Paulo: Cortez, 2003.

BRASIL. Constituição Federal de 1988. http://www.planalto.gov.br. Acesso em 20/12/2005.

. Lei de Diretrizes e Bases da Educação Nacional Nova LDB (Lei $n^{\circ}$ 9394/96). Rio de Janeiro: Qualithmark Editora, 1997.

- Lei de Diretrizes e Bases da Educação Nacional. (Lei n ${ }^{0}$ 5692/71). http://www.pedagogiaemfoco.br . Acesso em 20/12/2005.

- Ministério da Educação - Diretrizes operacionais para a educação básica nas escolas do campo. Brasília, DF, 2002.

- Ministério da Educação - Grupo Permanente de Trabalho de Educação do Campo. Referência para uma política nacional de Educação do Campo. Caderno de subsídios, Brasília, DF, 2005.

. Ministério da Educação e Cultura. Decreto $n^{o}$ 7.352/2010. DOU 05.11.2010. Dispõe sobre a política de educação do campo e o Programa Nacional de Educação na Reforma Agrária - PRONERA. Brasília, 2010.

. Ministério Extraordinário da Política Fundiária. Instituto Nacional de Colonização e Reforma Agrária. Programa Nacional de Educação na Reforma Agrária. Manual de Operações do PRONERA. Brasília, 2011.

Ministério Extraordinário da Política Fundiária. Portaria $n^{o} 10 / 98$, de 16 de abril de 1998. Cria o Programa Nacional de Educação na Reforma Agrária - PRONERA, vinculando ao Gabinete do Ministro e aprova o seu Manual de Operações.

CALDART, R. S. A Escola do Campo em Movimento. Currículo sem Fronteiras, v.3, n.1, pp.60-81, Jan/Jun 2003. Disponível em: 〈www.curriculosemfronteiras.org > e $<$ http://portal.mec.gov.br/secad >. Acesso em: 20 jun. 2008.

. Pedagogia do Movimento Sem Terra. São Paulo: Editora Expressão Popular, 2004.

- Por uma Educação do Campo: traços de uma identidade em construção. In: ARROYO, M.; MOLINA, M. C. (Org.). Por Uma Educação do Campo. Petrópolis, RJ: Vozes, 2005.

CANIVEZ, P. Educar o cidadão? Campinas, SP: Papirus, 1991.

CORAZZA, S. Planejamento de ensino como estratégia de política cultural. In: Antonio Flávio Moreira Barbosa. (Org.). Currículo: questões atuais. Campinas - SP: Papirus, 1997. 
FORQUIN, J.C.. Saberes escolares, imperativos didáticos e dinâmicas sociais. Porto Alegre, Teoria e Educação, n.5, pp.28-49, 1992.

. Currículo entre o relativismo e o universalismo. Revista Educação e Sociedade. Ano 21, $\mathrm{n}^{\circ} 72$ Dez, Campinas, 2000

FREIRE, Paulo. Pedagogia do oprimido. 18 a ed. Rio de Janeiro, Rj: Editora Paz e Terra, 1988. . Pedagogia da autonomia: saberes necessários à prática educativa. São

Paulo: Paz e Terra, 1996.

GIROUX, H. A. Praticando estudos culturais nas faculdades de educação In: SILVA, T. T. (Org.). Alienígenas na sala de aula: uma introdução aos estudos culturais em educação. Petrópolis: Vozes, 1995. p. 85-104.

GRAMSCI, A. Cadernos do cárcere. Maquiavel. Notas sobre o Estado e a política. 4.ed.,v.3. Rio de Janeiro: Civilização Brasileira, 2011.

KRAMER, S. Currículo: Políticas e Práticas, Campinas: Papirus, 2001.

LEITE, S. C. Escola rural: urbanização e políticas educacionais. São Paulo: Cortez, 1999.

MÉSZÁROS, I. Para além do capital. Rumo a uma teoria da transição. Trad. Paulo C. C.; Sérgio L. São Paulo: Boitempo Editorial, 2011.

MOLINA, M. C. e FERNANDES, B. M. O Campo da Educação do Campo. In: MOLINA, M. C.; JESUS, S. M. A. de. Por Uma Educação do Campo. Vol 05. Brasília, DF: Articulação Nacional "Por uma Educação do Campo",2005.

MOLINA, M. C. Entrevista. M. A. de S. Revista Caderno de Pesquisa: pensamento educacional. $\quad$ v. $4, \quad$ n.8, jul/dez. 2009. Disponível em: www.utp.br/cadernos_de_pesquisa/edicoes.html>. Acesso em: 25/01/2010.

ORTEGA, A. C., FONSECA, S.G. Política de Educação para o mundo rural brasileiro: entre a universalização e a diferenciação dos conteúdos. Ensino e Revista v. 12, Uberlândia: Edufu. 2004.

PROGRAMA DE APOIO CIENTÍFICO E TECNOLÓGICO AOS ASSENTAMENTOS DA REFORMA AGRÁRIA - PACTo - MG/TRIÂNGULO MINEIRO. Universidade Federal de Uberlândia. Relatório de Pesquisa, CNPq, 2006

SACRISTÁN, G. Compreender e Transformar o Ensino, Porto Alegre: ArtMed, 1998.

SILVA JÚNIOR, A. F. Saberes e práticas de ensino de História em escolas rurais (um estudo no município de Araguari, MG, Brasil). Dissertação (Mestrado em Educação). Faculdade de Educação, Universidade Federal de Uberlândia. Uberlândia, MG, 2007.

SILVA, L. H. e COSTA, V. A. Educação Rural. Revista Presença Pedagógica. v. 12 n. 69 mai./ju. 2006.

SILVA, M.V. e LÉLIS, U.A. Processos regulatórios na formação de professores de assentamentos sindicais agrários no âmbito do PRONERA. In: $35^{\text {a }}$ Reunião Anual da ANPEd, Porto de Galinhas: Anais, 2012 (no prelo). 
SOUZA, M.A. Educação, Escola e Povos do Campo: práticas educacionais em questão in: SOARES, L. et al (orgs). Convergências e tensões no campo da formação e do trabalho docente. Belo Horizonte: Autêntica, 2010.

Notas:

${ }^{1}$ Docente da Faculdade de Educação da Universidade Federal de Uberlândia, com atuação no Programa de PósGraduação em Educação (mvs@ufu.br).

${ }^{2}$ Docente da Faculdade de Ciências Integradas do Pontal da Universidade Federal de Uberlândia (silvajunior_af@yahoo.com.br)

${ }^{3}$ O GPTE, a partir do diagnóstico "Perfil da Educação no Campo", elaborado pelo INEP - Instituto Nacional de Estudos e Pesquisas Educacionais Anísio Teixeira, referente ao sistema de ensino formal no meio rural, procurou levantar instrumentos para a construção de uma política pública de educação que atendesse às demandas dos sujeitos do campo, concebendo-a como instrumento imprescindível para o desenvolvimento sustentável das populações do campo.

Recebido em março/2012

Aprovado em agosto/2012 